$11-15-2009$

\title{
Inhibitors of Bacterial N-Succinyl-L,L-diaminopimelic Acid Desuccinylase (DapE) and Demonstration of In Vitro Antimicrobial Activity
}

\author{
Danuta Gillner \\ Nicola Armoush \\ Richard C. Holz \\ Daniel P. Becker \\ Loyola University Chicago, dbecke3@luc.edu
}

Follow this and additional works at: https://ecommons.luc.edu/chemistry_facpubs

Part of the Chemistry Commons

Author Manuscript

This is a pre-publication author manuscript of the final, published article.

\section{Recommended Citation}

Gillner, Danuta; Armoush, Nicola; Holz, Richard C.; and Becker, Daniel P.. Inhibitors of Bacterial N-SuccinylL,L-diaminopimelic Acid Desuccinylase (DapE) and Demonstration of In Vitro Antimicrobial Activity.

Bioorganic \& Medicinal Chemistry Letters, 19, 12: , 2009. Retrieved from Loyola eCommons, Chemistry:

Faculty Publications and Other Works, http://dx.doi.org/10.1016/j.bmcl.2009.09.077

This Article is brought to you for free and open access by the Faculty Publications and Other Works by Department at Loyola eCommons. It has been accepted for inclusion in Chemistry: Faculty Publications and Other Works by an authorized administrator of Loyola eCommons. For more information, please contact ecommons@luc.edu. cc) (i) $\Theta$

This work is licensed under a Creative Commons Attribution-Noncommercial-No Derivative Works 3.0 License. (C) 2009 Elsevier 


\title{
Inhibitors of Bacterial N-Succinyl-L,L-diaminopimelic Acid Desuccinylase (DapE) and Demonstration of in vitro Antimicrobial Activity
}

\author{
Danuta Gillner ${ }^{\mathrm{a}, \mathrm{b}}$, Nicola Armoush, ${ }^{\mathrm{a}}$ Richard C. Holz ${ }^{\mathrm{a}}$, and Daniel P. Becker ${ }^{\mathrm{a}}$ \\ ${ }^{a}$ Department of Chemistry, Loyola University, 6525 North Sheridan Road, Chicago, IL 60626 \\ ${ }^{b}$ Department of Chemistry, Silesian University of Technology, Gliwice, Poland
}

This is where the receipt/accepted dates will go; Received Month XX, 2009; Accepted Month XX, 2000 [BMCL RECEIPT]

\begin{abstract}
The dapE-encoded N-succinyl-L,L-diaminopimelic acid desuccinylase (DapE) is a critical bacterial enzyme for the construction of the bacterial cell wall. A screen biased toward compounds containing zinc-binding groups (ZBG's) including thiols, carboxylic acids, boronic acids, phosphonates and hydroxamates has delivered a number of micromolar inhibitors of DapE from $H$. influenzae, including the low micromolar inhibitor L-captopril $\left(\mathrm{IC}_{50}=3.3 \mu \mathrm{M}, \mathrm{Ki}=1.8 \mu \mathrm{M}\right)$. In vitro antimicrobial activity was demonstrated for L-captopril against E. coli.
\end{abstract}

Bacterial infections are a significant and growing medical problem in both the United States and around the world. ${ }^{1}$ The CDC recently reported that there are now several strains of Staphylococcus aureus that are resistant to all known antibiotics including vancomycin. $^{2}$ These cases underscore the fact that limited numbers of drugs are available to prevent a simple Staph infections from becoming deadly. ${ }^{3}$ At least four other strains of common bacterial species capable of causing life-threatening illnesses (Enterococcus faecalis, Mycobacterium tuberculosis, Escherichia coli O157:H7, and Pseudomonas aeruginosa) are already resistant to nearly all drugs in clinicians arsenal comprised of more than 100 drugs. 4 Thus, the search for new antibiotics that target enzymes in unexplored bacterial biosynthetic pathways is critically important, as confirmed in Supuran's excellent review of bacterial protease inhibitors. ${ }^{6}$

The dapE-encoded N-succinyl-L,L-diaminopimelic acid desuccinylase (DapE) enzyme is a member of the mesodiaminopimelate (mDAP)/lysine biosynthetic pathway. ${ }^{7}$ The amino acids mDAP and/or lysine are essential components of the peptidoglycan cell wall for Gramnegative and most Gram-positive bacteria, providing a link between polysaccharide strands. ${ }^{7}$ Therefore, enzymes involved in the $\mathrm{mDAP} / \mathrm{lysine}$ biosynthetic pathway, including DapE, are potential antibiotic targets.
DapE's are small, dimeric enzymes (41.6 kDa/subunit) that require two $\mathrm{Zn}$ (II) ions per mole of polypeptide for full enzymatic activity. ${ }^{8,9}$ On the basis of sequence alignments with other aminopeptidases ${ }^{10}$ and several DapE gene sequences, all of the residues that function as ligands in the dinuclear active site of those enzymes are strictly conserved in DapE from Haemophilus influenzae. Studies on the E134A- and E134D- altered DapE revealed that E134 acts as the general acid/base in the hydrolysis of the substrate and is absolutely required for catalytic activity. ${ }^{11}$ Investigations on H67A- and H349A-altered enzymes together with construction of a three-dimensional homology structure of DapE from $H$. influenzae (generated using the X-ray crystal structure of the Apo-DapE from Neisseria meningitidis as a template with superposition on the structure of the aminopeptidase from Aeromonas proteolytica (AAP)) confirmed the identification of active-site histidine zinc ligands. ${ }^{12}$ Based on this homology model, the active site of DapE contains two $\mathrm{Zn}$ (II) ions at a distance of $\sim 3.30 \AA$ A (Figure 1). 


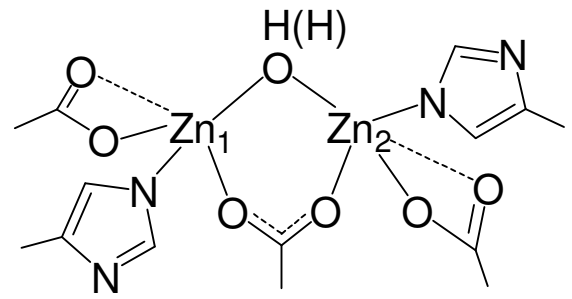

Figure 1. Proposed active site of DapE enzymes.

Each of the $\mathrm{Zn}$ (II) ions adopts a distorted tetrahedral geometry and is coordinated by one imidazole group (H67 for Zn1 and H349 for Zn2) and one carboxylate group (E163 for Zn1 and E135 for Zn2). Both Zn(II) ions are bridged by an additional carboxylate groups (D 100) on one side and water/hydroxide on the opposite side, forming a ( $\mu$-aquo)( $\mu$-carboxylato)dizinc(II) core with one terminal carboxylate and one histidine residue at each metal site.

In order to identify appropriate lead molecules for the inhibition of DapE, we have screened ${ }^{13}$ over thirty molecules representing various structural classes and containing different zinc-binding groups (ZBG's) using $\mathrm{N}$-succinyl L,L-diaminopimelic acid (L,L-SDAP) as the substrate. $^{14}$ These ZBG's include thiols, hydroxamates, carboxylic acids, boronic acids, and phosphates, and this fruitful initial screen has led to the identification of a number of low micromolar inhibitors (Table 1). We biased our initial screen to include bifunctional molecules that contained, in addition to the ZBG, a carboxylate moiety that could interact with the positively-charged lysine and/or arginine side chains that purportedly reside near the active site. Table 1 shows carboxylic acid-containing thiols that were found to inhibit DapE fairly potently. Even deltamercaptobutyric acid has an $\mathrm{IC}_{50}$ of $43 \mu \mathrm{M}$ versus DapE, and meta-mercaptobenzoic acid has a measured $\mathrm{IC}_{50}$ of $34 \mu \mathrm{M}$. L-penicillamine gave an $\mathrm{IC}_{50}$ of 13.7 $\mu \mathrm{M}$, and a measured $K_{\mathrm{i}}$ of $4.6 \mu \mathrm{M}$. DapE is stereoselective with respect to recognition of inhibitors, as D-penicillamine gave an $\mathrm{IC}_{50}$ of $50 \mu \mathrm{M}$. Given the success with these carboxylic acid-containing thiols, we turned our attention to captopril, which contains the requisite ZBG and carboxylate functionalities. LCaptopril exhibited an $\mathrm{IC}_{50}$ of $3.3 \mu \mathrm{M}$ and a measured $\mathrm{Ki}$ of $1.8 \mu \mathrm{M}$ (competitive). Again, the binding is stereoselective, as D-captopril ${ }^{15}$ was an order of magnitude less potent, with an $\mathrm{IC}_{50}$ of $42.0 \mu \mathrm{M}$.

Table 2 shows boronic acid derivatives that were tested as inhibitors of DapE. Phenylboronic acid itself was encouraging with an $\mathrm{IC}_{50}$ of $107 \mu \mathrm{M}$ and a measured $K_{\mathrm{i}}$ of $56.9 \mu \mathrm{M}$ (competitive). Incorporation of a carboxylic acid along with the boronic acid was not productive, as both 4-carboxyphenylboronic acid and 3carboxyphenylboronic acid did not inhibit DapE. It is hypothesized that geometric constraints may have
Table 1. Thiols tested as inhibitors of DapE

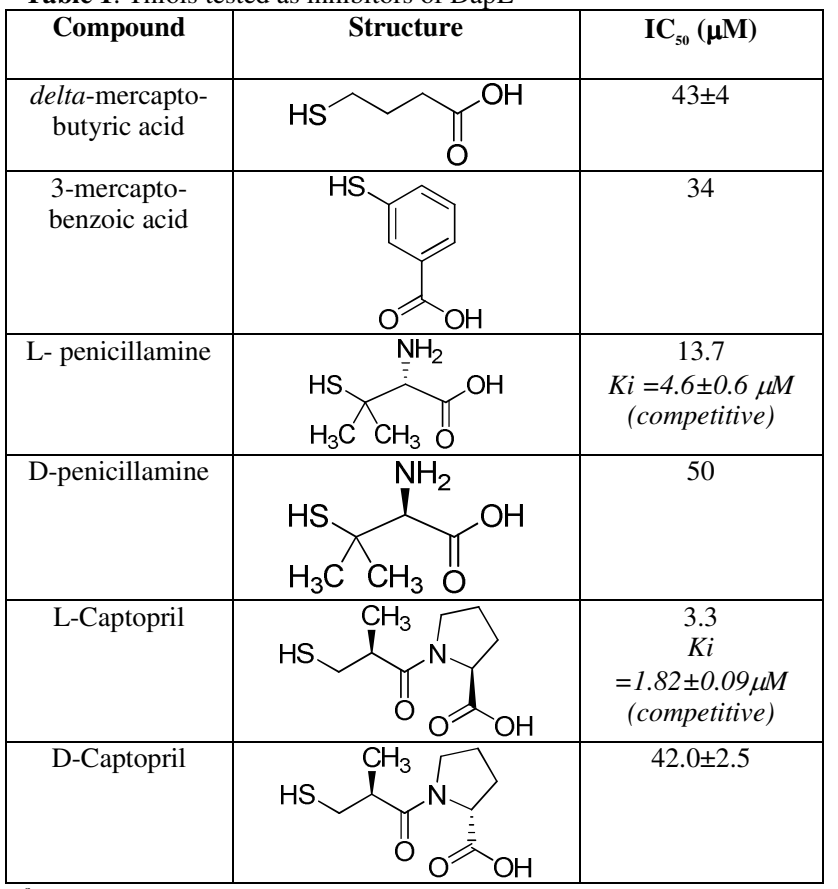

${ }^{\mathrm{a}}$ Values are means of three experiments, standard deviation is given in parentheses.

precluded a productive Coulombic interaction of the carboxylate with positively charged residues in the active site. Butylboronic acid was a weak inhibitor of DapE $\left(\mathrm{IC}_{50} \sim 10 \mathrm{mM}\right)$. 2-Thiopheneboronic acid was comparable to phenylboronic acid, with an $\mathrm{IC}_{50}$ of 92 $\mu \mathrm{M}$ and a measured $K_{\mathrm{i}}$ of $67 \mu \mathrm{M}$, but the inhibitor was noncompetitive. Surprisingly, 1-butaneboronic is only a very weak inhibitor of DapE $\left(\mathrm{IC}_{50} \sim 10,000 \mu \mathrm{M}\right)$ even though it is a potent inhibitor of AAP $\left(K_{\mathrm{i}}=10 \mu \mathrm{M}\right){ }^{16,17}$

Table 2. Boronic acid tested as inhibitors of DapE

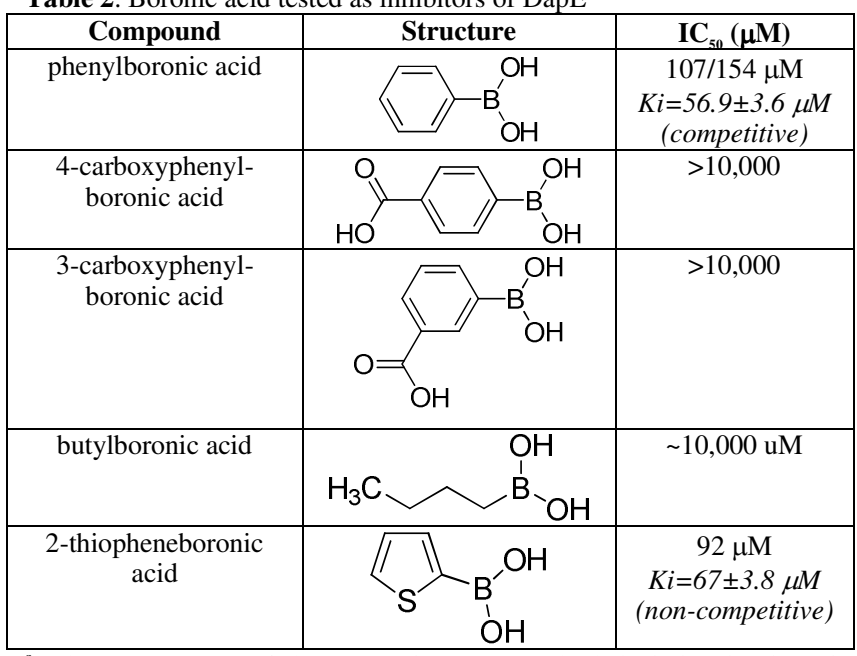

${ }^{\text {a }}$ Values are means of three experiments, standard deviation is given in parentheses.

Table 3 shows several other compounds that were screened versus the DapE enzyme. Given the very good potency of the ACE inhibitor L-captopril noted above $\left(\mathrm{IC}_{50}=3.3 \mu \mathrm{M}\right)$, the ACE inhibitor enalapril was 
screened, but did not show any potency versus DapE. Two simple hydroxamate compounds, acetohydroxamic acid and $\mathrm{N}$-(benzyloxycarbonyl)hydroxylamine (actually an N-hydroxy carbamate) were also screened but were too weak to measure the inhibitory potency. $\mathrm{N}$-Phenylthiourea could potentially function as a zincbinding compound and showed some inhibition of DapE, but the $\mathrm{IC}_{50}$ is greater than $100 \mu \mathrm{M}$. Phosphonic acids can also inhibit metalloproteases, and (2carboxyethyl)phosphonic acid was shown to have a very weak $\mathrm{IC}_{50}$ of $1,620 \mu \mathrm{M}$.

Table 3. Other potential inhibitors explored for the DapE enzyme

\begin{tabular}{|c|c|c|}
\hline Compound & Enalapril \\
(maleate salt)
\end{tabular}

${ }^{\text {a}}$ Values are means of three experiments, standard deviation is given in parentheses.

Several alkyl and aryl phosphates have also been tested in addition to diaminopimelic acid amides and ornithine amides (structures not shown). In all cases, these molecules exhibited little or no inhibitory potency $\left(\mathrm{IC}_{50}\right.$ $>1000 \mu \mathrm{M}->10,000 \mu \mathrm{M})$. Finally, (D,L)-(2phosphonomethyl)-pentanedioic acid did not inhibit DapE at concentrations up to $10 \mathrm{mM}$. 2-Carboxyethyl phosphonic acid is a significantly better inhibitor $\left(K_{\mathrm{i}}=\right.$ $800 \mu \mathrm{M})$ than phosphonoacetic acid, 3-phosphopropanoic acid, or $\mathrm{N}$-(phosphonomethyl)glycine, thus presenting an optimal chain length for interactions with DapE. We expect an optimal distance between thiol and carboxylate in the thiol series as well, depending on conformational mobility of the series.

We have confirmed antibiotic activity with the DapE inhibitor, L-captopril, in an antibiotic plate assay as illustrated in the following photos (Figure 2). Application of L-captopril directly to plates cultured with $E$. coli showed a dose-responsive antibiotic activity for this DapE inhibitor. Very little inhibition is observed for $1 \mathrm{mg}$ of L-captopril, but $5 \mathrm{mg}$ demonstrates a clear positive antibiotic result, and the zone of inhibition is even greater for $20 \mathrm{mg}$ of $\mathrm{L}$ captopril. Furthermore, this confirms that the enzyme inhibitor is crossing the bacterial cell membrane and reaching the desired target. The positive antibiotic control ampicillin is shown as well showing its zone of inhibition.

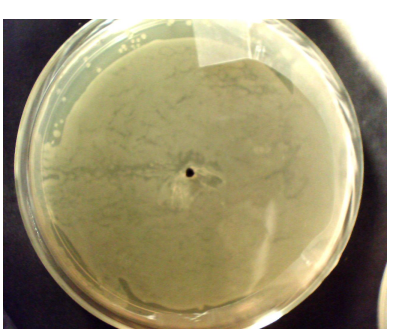

$1 \mathrm{mg}$ L-captopril

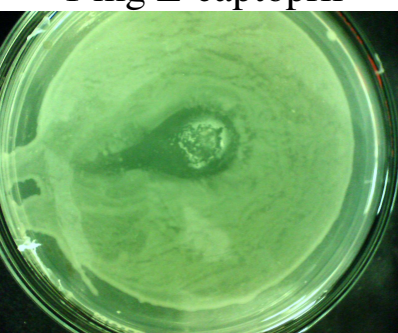

$20 \mathrm{mg}$ L-captopril

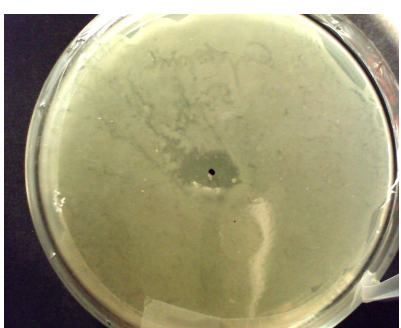

5 mg L-captopril

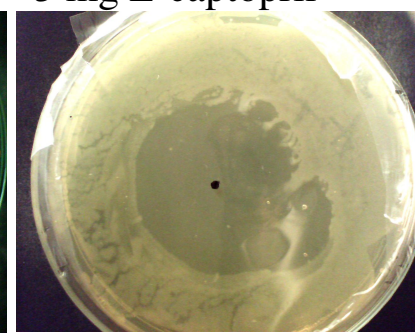

$1 \mathrm{mg}$ ampicillin
Figure 2. Antibiotic Activity of L-Captopril Against E. coli.

In summary, a screen of compounds containing ZBG's against DapE from Haemophilus influenzae has delivered a number of micromolar inhibitors including captopril, functioning as a competitive, reversible inhibitor with an $\mathrm{IC}_{50}$ of $3.3 \mu \mathrm{M}\left(\mathrm{K}_{\mathrm{i}}=1.8 \mu \mathrm{M}\right)$. Furthermore, antibiotic activity has now been demonstrated for the DapE inhibitor L-captopril. Captopril is an excellent lead for medicinal chemistry optimization in consideration of its low molecular weight (217) and low measured $\log \mathrm{P}$ of $0.34^{18,19}$ following the rules of Lipinski ${ }^{20}$ and containing few rotatable bonds, ${ }^{21}$ consistent with its known oral bioavailability.

\section{References and Notes}

1. Henry, C. M. $C \& E$ News. 2000, 41.

2. Anonymous. MMWR Recomm Rep. 1995, 44, 1.

3. Howe, R. A.; Bowker, K. E.; Walsh, T. R.; Feest, T. G.; MacGowan, A. P. Lancet. 1998, 351, 602.

4. Levy, S. B. Sci Am. 1998, 278, 46.

5. Chin, J. New Sci. 1996, 152, 32.

6. Supuran, C. T.; Scozzafava, A.; Clare, B. W. Bacterial protease inhibitors. Med. Res. Rev. 2002, 22, 329.

7. Scapin, G.; Blanchard, J. S. Adv Enzymol Relat Areas Mol Biol. 1998, 72, 279.

8. Bienvenue, D. L.; Gilner, D. M.; Davis, R. S.; Bennett, B.; Holz, R. C. Biochemistry (N Y). 2003, 42, 10756.

9. Born, T. L.; Zheng, R.; Blanchard, J. S. Biochemistry (N $Y$ ). 1998, 37, 10478.

10. Chevrier, B.; Schalk, C.; D'Orchymont, H.; Rondeau, J. M.; Moras, D.; Tarnus, C. Structure (Cambridge, MA, United States). 1994, 2, 283. 
11. Davis, R.; Bienvenue, D.; Swierczek, S. I.; Gilner, D. M.; Rajagopal, L.; Bennett, B.; Holz, R. C. JBIC, Journal of Biological Inorganic Chemistry. 2006, 11, 206.

12. Gillner, D. M.; Bienvenue, D. L.; Nocek, B. P.; Joachimiak, A.; Zachary, V.; Bennett, B.; Holz, R. C. JBIC, J Biol Inorg Chem. 2009, 14, 1.

13. Inhibition studies were performed in $50 \mathrm{mM}$ chelexed potassium phosphate buffer $\mathrm{pH}$ 7.5. A $3 \mathrm{mM}$ solution of DD,LL-SDAP in the same buffer was used for $\mathrm{IC}_{50}$ determinations. $\mathrm{K}_{\mathrm{i}}$ values were determined using 0.5$4.5 \mathrm{mM}$ substrate concentrations and different inhibitor concentrations (depending on the inhibitor). Total volume of the mixture was $1 \mathrm{~mL}$. For a more detailed summary of experimental details, see the Supporting Information.

14. Holz, R. C.; Gillner, D.; Becker, D. Abstracts of Papers, 237th ACS National Meeting, Salt Lake City, UT, United States, March 22-26, 2009; Abstracts of Papers,

237th ACS National Meeting, Salt Lake City, UT, United States, March 22-26, 2009. 2009, INOR-612.

15. Smith, E. M.; Swiss, G. F.; Neustadt, B. R.; Gold, E. H.; Sommer, J. A.; Brown, A. D.; Chiu, P. J. S.; Moran, R.; Sybertz, E. J.; Baum, T. J Med Chem. 1988, 31, 875.

16. Baker, J. O.; Prescott, J. M. Biochemistry. 1983, 22, 5322.

17. De Paola, C. C.; Bennett, B.; Holz, R. C.; Ringe, D.; Petsko, G. A. Biochemistry (N Y ). 1999, 38, 9048.

18. Ranadive, S. A.; Chen, A. X.; Serajuddin, A. T. M. Pharm Res. 1992, 9, 1480.

19. Moss, G. P.; Gullick, D. R.; Cox, P. A.; Alexander, C.; Ingram, M. J.; Smart, J. D.; Pugh, W. J. J Pharm Pharmacol. 2006, 58, 167.

20. Lipinski, C. A.; Lombardo, F.; Dominy, B. W.; Feeney, P. J. Adv Drug Deliv Rev. 1997, 23, 3.

21. Veber, D. F.; Johnson, S. R.; Cheng, H. Y.; Smith, B. R.; Ward, K. W.; Kopple, K. D. J Med Chem. 2002, 45, 2615. 